\title{
STEM and STEAM and the Spaces Between: An Overview of Education Agendas Pertaining to 'Disciplinarity' Across Three Australian States
}

\author{
Abbey MacDonald ${ }^{\mathrm{a}}$, Jane Hunter ${ }^{\mathrm{b}}$, Kit Wise ${ }^{\mathrm{c}}$, Sharon Fraser ${ }^{\mathrm{a}}$ \\ ${ }^{a}$ University of Tasmania, Australia; ${ }^{b}$ University of Technology Sydney, Australia; \\ ${ }^{c} R M I T$ University, Australia
}

\begin{abstract}
This article presents an overview of how interdisciplinary education agendas are being interpreted and enacted within three Australian states: New South Wales, Tasmania and Victoria. A comparative discussion is offered to ascertain the common and contrasting inhibitors and enablers of these agendas, specifically approaches to STEM and STEAM across the three states. Consideration is given to the priorities espoused in current State and Federal policy agendas. The article explores how disciplinary acronyms such as STEM and STEAM are being mobilised to empower or exclude particular disciplines, and how this implicates upon enactment of the three dimensions of the Australian Curriculum. By focusing on the contested spaces between these disciplines, the distinctiveness and potential of various interdisciplinary agendas can be better understood. In turn, ways of recognising, embracing and prioritising different forms of disciplinary knowledge can be identified in the spaces between disciplinary curriculum and pedagogy. These diverse ways of knowing are posited as integral to equipping young people for uncertain futures.
\end{abstract}

Keywords: STEM, STEAM, interdisciplinarity, interdisciplinary education

\section{'What happens between disciplines stays between disciplines': A preface for acronym extrapolation}

The STEM acronym has become ubiquitous in the $21^{\text {st }}$ century, with little need to remind readers that it refers to the disciplines of Science, Technology, Engineering and Mathematics. What is less well known is that the National Science Foundation in the United States of America (U.S.A.) originally coined STEM for a strategic purpose in the 1990's. Its purpose was to recognise the importance of the four STEM disciplines in the economy and as a basis for innovation (Moore, Johnson, PetersBurton \& Guzey, 2016). Further to influencing thinking about the relationship between these four disciplines, combining them into the STEM acronym also contributed to the creation of both alliances and hierarchies, which have underpinned and influenced policy and educational trends from the 1960s to the present day (Mohr-Schroeder, Cavalcanti, \& Blyman, 2015). More recently, other disciplinary acronyms have emerged in scholarly literature, most notably STEAM, which seeks to emphasise the potential for the Arts to contribute powerfully to disciplinary commentary around the importance of creativity and design for innovation, entrepreneurialism and reimagined work (Costantino, 2018; Craft, 2011; Yakman, 2008; Yakman \& Lee, 2012). Beyond the disciplinary alliances underpinning STEM and its mandate to respond to economic priorities (Saunders, 2009), attention continues to focus on educational reforms that ensure workforce-ready STEM graduates are a priority in tertiary education. To allow such a vision can come to fruition, it is essential that interdisciplinary education

\footnotetext{
${ }^{1}$ Corresponding Author. Abbey MacDonald, College of Arts, Law and Education University of Tasmania, Locked Bag 1307, Launceston, TAS, 7250 Email: abbey.macdonald@utas.edu.au

MacDonald, A., Hunter, J., Wise, K., \& Fraser, S. (2019). STEM and STEAM and the spaces between: An overview of education agendas pertaining to 'disciplinarity' across three Australian states. Journal of Research in STEM Education, 5(1), 75-92.
} 
agendas are driven by teaching that is inspirational, meaningful and transformative for all students (Tregloan, Wise \& Fountain, 2018).

The emergence of various acronyms drawing together different discipline areas serves many functions as well as dysfunctions in Australia, depending on how the particular interdisciplinary acronym is interpreted and then enacted. Discussion pertaining to the relationship between STEM and STEAM education in Australia continues to draw significant coverage across scholarly inquiry, political speech and in mainstream media. The challenges and benefits inherent to enacting agendas associated with STEM and STEAM have piqued the attention of academics, politicians and public commentators alike (Colluci-Gray et al., 2017; Colluci-Gray et al., 2019; Yakman \& Lee, 2012). It can be broadly inferred from STEM and STEAM scholarly literature and commentary in Australia, that running parallel to this conversation, research and curriculum developers continue to grapple with different, disparate or conflicting interpretations of how [inter]disciplinary education unfolds in the move from theory to practice (MacDonald \& Wise, 2018; Taylor, 2016). However, the question of whether such acronym grappling meaningfully shapes or distracts from a successful, inclusive and holistic education experience remains.

In school education contexts, this struggle and associated ambiguity, runs concurrent to teachers and students across the country enacting their own possibilities of what multi, cross and other prefixes for '- disciplinary' education can look like. While 'interdisciplinary' captures the broad range of combinations implied, each represents a distinct approach to combining disciplinary conditions, ranging from the additive (multidisciplinary) to the transformative (transdisciplinary) (Davies \& Devlin, 2010); yet each requires clarity on their defining qualities, specific goals, approaches and conditions to succeed.

An emerging realisation is that while uncertainty around practical applications of disciplinary education acronyms poses challenges, indecision also creates problems, and problems in turn provide opportunity for reimagination and innovation (MacDonald \& Wise, 2018). In the uncertain spaces, or nexus points where disciplines interrelate (whether STEM, STEAM or something else), the implications of their relationality and potential interconnections warrant further inspection.

The body of emerging literature around STEM and STEAM education posits that in order for such interdisciplinary approaches to be achieved, an understanding of the practice of STEM must first be established (Cunningham 2018; Liao, 2016; Radizwill, Benton \& Moellers 2015). Recognition of the equal value associated with different ways of knowing, and an appreciation of the distinctive lenses brought to knowledge by each discipline is needed before the environments and circumstances necessary to hold interdisciplinary practices can be articulated (Marshall, 2014). Our ability to recognise the equal value and distinctiveness of disciplines is thwarted in any discipline acronym arrangement that promotes or demotes disciplines or seeks to exclude disciplinary fields.

A significant contention underpinning the commentary around STEM and STEAM is disciplinary hierarchies; inherent, often binary perspectives and/or biases, that privilege one or more disciplines over another in an interdisciplinary education context. The term "disciplinary egocentrism" describes the lack of student readiness to engage in multidisciplinary education (Paretti, 2011), however, the term can also be applied to a wide range of key education stakeholders, such as teachers, academics and indeed STEAM industry experts who are unable or unwilling to value alternative approaches to their respective discipline areas (Yoder, Bodary \& Johnson, 2016).

A perspective offered by Liao (2016) compels STEM and STEAM theorists and practitioners to divert their attention from attempts to reconcile hierarchal disciplinary competition, to instead invest their attention and efforts to context and in the spaces between disciplines. For example, an arts-integrated approach to STEAM education, where teaching and learning concentrate on and derive from the liminal and relational 'inter-spaces' between disciplines, can open up a transdisciplinary 
space - a transformative space that is at once oriented between, across and beyond all disciplines (Davies \& Devlin, 2010; Hobbs, Cripps-Clark \& Plant, 2018; Liao 2016). If we are to consider what this dissolution of discipline hierarchy may look like in a STEM education context, Nadelson \& Seifert (2017) champion the need for seamless amalgamation of content and concepts so that "knowledge and process of the specific STEM disciplines are considered simultaneously without regard for the discipline, but rather in the context of a problem, project or task" (p. 221).

Such examples are indicative of how some STEM and STEAM theorists are working to resist the distraction that discipline hierarchy arguments create for efforts to shift away from perceived arbitrariness of any particular discipline acronym. An emergent body literature is establishing the need to move beyond disciplinary politicking and instead look beyond the acronyms themselves and concentrate on their interdisciplinary enactments in context (MacDonald \& Wise, 2018; Tytler, Williams, Hobbs \& Anderson, 2019). Before such aspirations can be realised however, there is a need to recognise and be mindful of the myriad challenges these ongoing movements mean for teachers; the work they have already done and continue to do to enact interdisciplinary education agendas and priorities such as STEM and STEAM. In Australia, an array of intersecting national, state and education sector specific STEM education strategies (see Education Council, 2015; NSW Department of Education, 2018; Tasmanian Department of Education, 2015, 2017) have been developed, with educators investing considerable time, effort and energy in their grappling with and adoption of the vernacular inherent to these strategies in their classroom enactment of STEM education. To hurry past the already significant investment of federal and state policy think-tanks, and ongoing efforts teachers are making to achieve the visions of interdisciplinary education strategies that perpetuate the same disciplinary acronyms we might ask them to look beyond is problematic. For decades already, "educational reform in Australia has been a quagmire of political and educational agendas, with a myriad of known factors (of which change fatigue is a part) that have enhanced or hindered implementation" (Dilkes, Cunningham \& Gray, 2014, p. 46). In order to avoid education reform fatigue, any shifting away from the vernacular and challenges inherent to disciplinary acronyms needs careful consideration. In order to transcend perpetuation of disciplinary acronyms, the foundations of the tensions that exist between the disciplines must be understood and reconciled, and while the acronyms at present may not well serve the interdisciplinary education 'end game', they are an integral and significant part of the education reform journey. Bearing in mind that cynical, realistic and even enthusiastic teachers suffer reform fatigue after years of rapid and continual change (Dilkes et al., 2014; Savage, 2016), it is imperative that teachers be given time, space and voice in defining the reconciliation and transcendence of disciplinary acronym perpetuation. The focus for conceptualisation and operationalisation of interdisciplinary education can then purposefully orient itself towards recognising and understanding how context and differentiation implicate enactment, Given the absence of a universally agreed-upon definition of what STEM education embraces, it can be inferred that each country establishes their own definition. In Australia, the National Strategy in STEM Education (Education Council, 2015) refers to:

... the teaching of the disciplines within its umbrella - science, technology, engineering and mathematics - and also to a cross-disciplinary approach to teaching that increases student interest in STEM related fields and improves students' problem solving and critical analysis skills (Educational Council, 2015, p. 5).

In their literature and policy review of the challenges faced in STEM learning in Australian schools, Timms, Moyle, Weldon and Mitchell (2018) highlight both the importance of disciplinary knowledge and the need to shift the educational focus towards "the practices and ways of thinking in each discipline" (p. 21). This need to shift is emblematic of the culture of 'reform fever' (Savage, 
2019) implicating upon policy enactment within out contemporary Australian education. While some policies "might give an illusion of stability, a wider view ultimately reveals constant motion and new beginnings" (Savage \& Lewis, 2018, p. 124, emphasis in original). In integrated STEM education, there is an emphasis on "real-life contexts and the development of proto-types or models to similar authentic problem-solving or decision-making scenarios" (Fraser, Earle, Fitzallen, 2019, p. 15). Such an approach is different from traditional STEM pedagogies and cannot be pursued without significant deviations in both curricula and conventional teaching methods. The successful integration of creative arts and other disciplinary approaches in STEM teaching and learning contexts requires teachers capable of learning how to teach alternative disciplinary approaches; as well as an evidence base that justifies such (Bequette \& Bequette, 2012).

The Australian Curriculum is organised into three distinct components, or dimensions, comprising three Cross-Curriculum Priorities (CCPs), seven General Capabilities (GCs) and eight Learning Areas (LAs). The Australian Curriculum, Assessment and Reporting Authority (ACARA, 2017) present the whole Australian Curriculum as a three-dimensional curriculum that "recognises the central importance of disciplinary knowledge, skills and understanding" (p. 1) inherent to LAs in relation to GCs and CCPs. The three dimensions are positioned in a non-hierarchal and interrelated structure, creating space and aspiration for a wholly mobilised and richly relational curriculum that holds integration and interconnectedness at its core. This three-dimensional interpretation offers an inter-related, rounded whole; with detail within each of the three dimensions differentiating learning areas into distinct subject/ discipline areas, and a suite of defined skills, capabilities and priorities. This vision of learning outcomes that enables discipline knowledge, skills, behaviours and dispositions to be fostered across subject-based content, general capabilities and cross-curriculum priorities is contingent upon a teachers' preparedness and capacity to enact interdisciplinary teaching (Harris \& de Bruin, 2017). If teachers are to meet the challenge of equipping students "to be lifelong learners and be able to operate with confidence in a complex, information-rich, globalised world" (ACARA, 2017 , p. 1), it is pertinent to consider how our present school structures serve to enable or inhibit the ambition of a three-dimensional curriculum.

Opening conversation across the common spaces and thresholds of different education contexts, such as secondary and tertiary, can allow different levels of education to share approaches to interdisciplinary activity and these ambitions for a three-dimensional curriculum. Further to this, considering connections across levels of education is essential for the identification of overarching, systemic challenges to authentic interdisciplinary ways of knowing.

While a discussion of the pedagogic approaches that enable the successful integration of creative and other disciplinary approaches in STEM teaching and learning contexts is outside the scope of this paper, the Office of Learning and Teaching Discovery and Innovation project 'Multiple Measures' (Tregloan, Wise \& Fountain, 2016) provides some insights. Focussing on the tertiary sector, this national survey of approaches to interdisciplinary assessment design considered two broad goals for interdisciplinary learning: deepening expertise by drawing in related skill sets and knowledge; and, broadening skills - include the 'soft' skills arguably favoured by future employers (Jefferson \& Anderson, 2017) - and ways of knowing by engaging with dispersed disciplinary fields.

The ways in which interdisciplinary education is being delivered in the Australian tertiary context can inform how interdisciplinary teaching and learning is understood and transferred to other levels. For example: how do we move beyond the model of the 'T-shaped' learner, often associated with the tertiary sector and AQF Levels 7-10? The notion of the T-shaped skillset developed in the late 1970s through analysis of management practices and entered mainstream vocabulary and commentary in the 1990s. Interestingly, it remains especially prevalent in the classic STEAM domain of software development. By analysing Australian tertiary case studies based in the Humanities and 
Creative Arts, the Multiple Measures project also identified examples of teaching approaches that enabled both depth and breadth: combining the self-directed, single focus, long duration of the depthorientated project, with the scaffolded, multi-parted, often collaborative approach of breadth case studies. Rather than the familiar 'T-shaped' acquisition of skills, where depth and then breadth are developed independently and sequentially, these projects suggested the simultaneous development of depth and breadth: developing a rounded and dimensional 'X-shaped learner' (Tregloan, Wise \& Fountain, 2018).

The potential to employ relational and reciprocal insights from and across the spectrum of tertiary, secondary and education contexts is worthy of further exploration, as is consideration of the different enablers and inhibitors teachers encounter across different contexts. To do so is to extend the notion of non-hierarchal discipline privileging in order to recognise insights pertaining to pedagogical content knowledge practiced across the gamut of education contexts (MacDonald, 2019). For example, the findings from the Multiple Measures project assume a level and depth of disciplinary knowledge, which may not always be present for those teachers working in early and primary years of schooling (Cunningham, Perry \& Stanovich, 2004). However, they do suggest ways to integrate modes of learning associated with different knowledge domains, as well as identifying potential barriers for successful enactment of learning modes in contexts that impact tertiary education. In relation to the secondary education space, the findings reiterate the challenge for teachers working in siloed disciplines, or subject areas, aligning powerfully with Marshall's (2014) call for transformation of the constraints that disciplinary silos pose for teachers working in the secondary schooling system. Transformation of the ways in which engagement and interaction is enacted across the spectrum of education levels is necessary if we are to "inspire new models of practice in an education system sorely in need of change" (Marshall, 2014, p. 125), and deliver on the full potential envisioned in our three-dimensional Australian Curriculum.

These commentaries indicate the need to remain open to and mindful of the potential for interdisciplinary approaches to teaching and learning, and how these aspirations can manifest innovative and workforce-ready education outcomes. To better understand what STEM and STEAM education can achieve, one approach may be to pay closer attention to the ambiguous 'in-between spaces' of the disciplines contained without the eight LAs of the Australian Curriculum, and how the GCs and CCPs can be enacted as disruptors that foster interdisciplinarity education, for transdisciplinary outcomes. Also emerging from these commentaries is a need for further consideration to be given to the threshold spaces between education contexts and levels that might yield fresh insights for how we theorise and achieve relationality between disciplinary ways of knowing and interdisciplinary pedagogy.

\section{Entwining Disciplinary Perspectives Across Three Australian States}

The authorship team who developed this article work across a diverse range of disciplinary backgrounds and education contexts pertaining to STEM and STEAM education. As such, this article is an entwined narrative that draws from and across our respective STEM and Arts industry collaborations, as well as teacher education and tertiary education contexts. We also acknowledge that our elicitation of insights and subsequent meaning making emerges from our individual perspectives of disciplinary expertise in those contextual spaces, which include strengths in Science, Mathematics, Humanities and the Creative Arts.

Abbey MacDonald is an artist, teacher and researcher working in Higher Education (Arts teacher education) at the University of Tasmania. She is an arts-based researcher who works in scoping relational intersections between arts-based methodology and pedagogy (see MacDonald, 
Baguley \& Kerby, 2017) and interdisciplinary applications in teacher professional learning contexts (see MacDonald, Hunter, Ewing \& Polley, 2018). MacDonald's priority research contexts include brokering professional learning collaborations (see MacDonald \& Wightman, in press), enacting interdisciplinary curriculum (see MacDonald \& Polley, 2019) and cultivating broad community values in and through Arts education contexts. Further to her work in Arts teacher education and professional learning, MacDonald advocates for access to quality Arts education for all Australians through her role as vice president of Art Education Australia, which is the peak national body for visual art education in the country.

Jane Hunter works from the STEM Education Futures Research Centre at the University of Technology, Sydney in New South Wales (NSW), where she has conducted a series of STEM Category 2 funded research studies in public schools (2016-18). To date, the work has involved 14 NSW primary schools, more than 59 teachers and approximately 1500 students aged 5-12 years. The three mixed methods studies included professional learning (PL) with a pedagogical focus using the High Possibility Classrooms (HPC) framework (see Hunter, 2013; 2015); conducted in schools for 3 - 15 months. This research was designed to build teacher capacity and middle leader agency in STEM education, which when enacted in programming and in classrooms often became STEAM with the 'natural inclusion' of the Arts and the Social Sciences. Participants used inquiry, project-based and design challenge approaches underpinned by the High Possibility Classrooms (HPC) framework (see Hunter, 2017).

Kit Wise has engaged in an advisory capacity with creative arts schools on course design and interdisciplinarity around the world, including Singapore, New Zealand, Canada and Australia. His interest in K-12 STEAM education builds upon the successful Office of Learning \& Teaching Innovation \& Development grant Benchmarking quality assessment tasks to facilitate interdisciplinary learning in the creative arts and humanities. Wise collaborates with MacDonald and other colleagues across various disciplines to explore the application of those findings within tertiary contexts, potential translations and insights for school education and wider disciplinary networks, as well as the specific interdisciplinary field of STEAM education (see MacDonald \& Wise, 2018; MacDonald et al., 2018).

Sharon Fraser's involvement in Science and Mathematics Education research since 2013 in Tasmania has a distinct focus on integrated STEM education. Capacity building through Professional Learning (PL) has always been the driver for her engagement in research, and in particular in PL for teachers in rural, regional and remote settings (Fraser et al., 2019) and/or those teaching out of field (Beswick, Fraser \& Crowley, 2016).

Fraser's research focuses on collaborative 'STEM' education research, by bringing together a team of academics with complementary research interests and capabilities, in order to re-conceptualise the notion of 'integrated STEM'. Recent and ongoing Category 2 research funded projects continue to focus on PL, but with a renewed focus upon leadership, whole of school approaches, and a capability approach to capacity building. Leadership is an essential element in developing school culture, which embraces interdisciplinary approaches to learning and teaching in the face of an Australian Curriculum that sustains disciplinary siloes. Fraser's research to date embraces a continuum - incorporating cascading STEM education capabilities for principals, teachers, students, the community and the educational researchers - that are essential for effective evidence-based, interdisciplinary and integrated STEM education.

\section{Methods, Mediums and Design: Architecture for Imagining Disciplinary Possibilities}

In order for the authorship team to provide insight into how we discerned various disciplinary STEM and STEAM education agendas being interpreted and enacted within three Australian states, 
a reflective analytic process was adopted. From our different contextual positions of disciplinary expertise, the authorship team adopted a constructivist approach to facilitate vibrant discussion and the sharing of perspectives. Through articulation and involvement of individual storylines we "collaborated in the telling and retelling of stories of what has past, and in the co-creation of stories for the present and the future" (Beattie, 1995, p. 65). This methodology, of distilling and examining individual lived experiences and observations, feeds into a 'writing of stories' towards collective applications and possibilities. This in turn creates space for the transformation of living stories, and articulation of possibilities for future storylines to converge (Leggo, 2008).

The propositional question framed to facilitate initial entry points for data generation was:

- What policy, reforms, reports, priorities and trends are driving/shaping interdisciplinary education agendas within the context of the Australian states in which we work? (NSW, Tasmania, and Victoria)?

Using this initial question to frame our approaches, we independently revisited our individual experiences of working in higher education contexts in teacher education and the creative arts, to consider how we were encountering disciplinary acronyms, such as STEM and STEAM, and how we have observed their mobilisation within broader disciplinary agendas. From this focus, we each developed a short storied vignette, for the purpose of sharing, reflective analysis and collective meaning making. Individual storied vignettes enabled us to construct a profile of various disciplinary profiles within our respective state contexts for the purpose of sharing and meaning making. These profiles were constructed in consideration of the events we determined, from our positions of encounter and expertise, to be critical to shaping predominant mobilised ambitions; and, the degree to which these enable and/or inhibit the realisation of STEM, STEAM or other disciplinary agendas, in and for school education contexts. The authors engaged with each other throughout the research process in ways akin to that of bricoleurs (Levi-Strauss, 1962), adopting co-constructive interpretations of individual and collective strategies, in order to make sense of our lived experiences of working relationally in higher education / teacher education contexts.

After the formation of vignettes, a second stage of data generation and meaning making was employed, from which two sub-questions emerged:

i) What are the common and/or contrasting critical events underpinning the formation and enactment of these disciplinary agendas; and

ii) How are these critical events impacting on approaches to STEM and STEAM education in our respective Australian state contexts?

These two sub-questions provided a common threshold for further encounter, as well as supporting discussion regarding thematic commonalities that emerged across the vignettes (MacDonald, Hunter, Ewing \& Polley, 2018). Through this entwined process of retrospection and reflection, we intersected individual and shared dialogue to develop critical storylines, from superfluous 'like' and 'other' through lines (Webster \& Mertova, 2007). This multi-layered process of data generation and critical reflection identified both synergies and contrasting approaches to distinct disciplinary agendas unfolding in New South Wales, Tasmania and Victoria. The accumulation of critical storylines facilitated the authors to draw mean between critical events "to index answers which the whole set can offer to the problem" (Levi Strauss, 1966, p. 12).

Allowing the prioritisation of specific disciplinary hierarchies to be made explicit provides a means to index possibilities for the bigger picture problem (Levi Strauss, 1966). In so doing, we adapt McCarthy et al.'s (2001) proposition to interrogate and reframe how we encounter storylines that might advocate for the inclusion or exclusion of particular disciplines in education contexts. The architecture of this process aligns with what Beattie (1995) describes as a collaborative, qualitative approach where the concept of interacting storylines is used to "further explore the meanings of 
teaching, learning and professional interactions" (p. 66).

\section{Vignettes of Professional Contexts: How NSW, TAS and VIC Interpret and Enact Disciplinary Agendas in Education Contexts}

The following section identifies the outcomes of the methodological process the authorship team used to distil the critical storylines that capture what is happening in relation to STEM, STEAM and/or the potential for other disciplinary agendas in the three respective states. The vignettes elicit insight into individual experiences of, contributions to, and/or the implications of being subjected to the disciplinary agendas in which the authors work. Drawing on these three vignettes, further discussion focuses on an entwined meta-storyline, where the critical themes, enablers and inhibitors operating across contexts are identified, leading to more incisive consideration of their implications and possibilities.

\section{New South Wales}

Distinct from the other states New South Wales (NSW) does not have a stand-alone STEM or STEAM education strategy (Gotsis, 2017). It does however have an innovation strategy and documentation cites NSW as having satisfied the National STEM School Education Strategy 20162026 (Education Council, 2015) by developing online resources, 14 action schools, minimum standards for the Higher School Certificate (HSC), strengthening teaching standards and reforming the curriculum by introducing iSTEM electives in the later stages of schooling (NSW Department of Finance, Services and Innovation, 2015). In NSW a range of other undertakings are shaping the study of what is deemed integrated STEM in primary and secondary public schools, that include its investment in Education for a Changing World agenda on the strategic implications that advances in technology will have for education (Loble, Creenaune \& Hayes, 2017).

NSW is a jurisdiction with more than 1 million students serviced by 2400 schools. Since 2017 the effort has revolved around "the delivery of quality STEM education for all students to ensure:

- raising expectations and enhancing the quality of student learning in STEM

- fostering quality teaching and leadership in STEM

- innovative ways of delivering STEM education" (NSW Department of Education, 2018).

The language of the various STEM websites principals, schools and teachers can access are primarily concerned with quality STEM, authentic experiences, project-based learning and a focus on the final years of primary schooling onwards into secondary education. In addition to that previously mentioned, STEM education provision is supported by two dedicated STEM advisors, a team of experienced curriculum advisors in Science, Technology and Mathematics, the STEM share program of kits of 'hands on' loaned resources (\$23 million program funded by the NSW State Government), mentoring programs, online templates, teacher surveys to understand what schools are doing in STEM, participation in the Principal as STEM Leaders (PASL) research study, STEM school and industry partnerships and bespoke professional learning resources that all teachers can access alongside national assets from the CSIRO and so on. Within the activities/resources are six principles of STEM education that give voice to the pedagogical drivers (STEM NSW Department of Education, 2017):

1. To activate and build students' prior knowledge.

2. To provide opportunities for students to organise information and understand influences and how they learn and apply new knowledge.

3. To generate students' motivation that determines, direct and sustains what they learn in STEM. 
4. To develop fluency and automaticity to ensure students must acquire component skills, practise integrating them and know when to apply what they have learned in STEM

5. To foster goal-directed practice combined with effective feedback to enhance quality of learning using design challenges and feedback from peers, teachers and self-evaluations of their solutions.

6. To become self-directed learners to enable monitoring and adjustment of their approaches to learning.

Furthermore, the NSW Education Standards Authority (NESA) has developed a number of cross curriculum sample units in STEM; advice on programming is provided alongside outcomes that target the Mathematics, Science and Technology syllabus documents from K-12. The place of an interdisciplinary focus for STEM in policy documentation revolves around pedagogy, specifically inquiry, collaboration and design thinking. STEAM education on the other hand receives scant citation in key reports and in one brief mention in website documentation it refers to STEM education in South Korea and that without the Arts, creativity and engagement in the STEM disciplines would suffer (Gotsis, 2017). Outside stated directives some individual schools are declaring a focus on STEAM through maker spaces and 'future-focused learning'. The main conversation in NSW public schools revolves around the need for STEM education to bolster declining education outcomes since 1995 and in particular, in two disciplines, Mathematics and Science.

\section{Tasmania}

Despite being Australia's smallest state, Tasmania is experiencing rapid growth in its population and has the fourth best performing economy in the country (CommSec, 2018). It continues to experience significant socio-economic challenges, with the lowest level of educational attainment in Australia (Allen et al., 2017). The Tasmanian education system is unusual in that in the Government sector in particular, the education system traditionally incorporates an extra transition point for students continuing onto year 12, requiring students to leave their district school to attend a College located in one of the major cities (Hobart, Launceston, Burnie or Devonport). Further to this, Tasmania is reported to experience "persistent underperformance in the transition to Year 10 and subsequent retention rates to Year 12" (Stratford et al., 2016, p. 4). It is estimated that Tasmania is 10,000 tertiary enrolments behind the next lowest performing state (Department of Premier and Cabinet, 2018), with significant challenges in encouraging students to complete Years 11 and 12

At the same time, Tasmania is host to arguably one of the most vibrant interdisciplinary creative community in Australia (Grimmer, 2017; Lehman \& Reiser, 2014), as exemplified in a thriving local, interstate and international art exhibition calendar, and annual festivals such as the Museum of Old and New Art (MONA)'s DARK MOFO winter festival, the MONA FOMA summer festival and Junction Arts Festival (JAF). A significant feature of the Tasmanian context is the 'STEAM' interests of many of these festivals and institutions; most notably, MONA, which has sustained record of curating world-acclaimed art/science exhibitions.

Like all Australian states, STEM education in Tasmania draws its focus from the National STEM Education Strategy (2015). Both government and non-government within the state have developed their own responses to this strategy and are currently at different stages of implementation. The Tasmanian Department of Education (2015) commits to an interdisciplinary approach to STEM education in which:

STEM approaches highlight connections between the learning areas of Science,

Mathematics and Technologies (which can include engineering) and the broad capabilities

and dispositions learners will need in a rapidly changing world. (para. 2)

Leadership is an essential element in developing a school culture, which embraces interdisciplinary approaches to learning and teaching in the face of an Australian curriculum that 
presents disciplines as 'siloes'. Our current research embraces a capability continuum- incorporating cascading STEM education capabilities for principals, teachers, students, the community and the educational researchers - that are essential for effective evidence-based, interdisciplinary and integrated STEM education.

For STEM education in Tasmania, teachers are encouraged to engage learners with concepts from the disciplines of science, mathematics, technology and engineering (design and technology) through real world and authentic projects and challenges. In support of this goal, a STEM Framework (2017) has been developed, encompassing Tasmanian Government school learners from the Early Years to Year 12. Its goals, objectives and five principles align with the National STEM School Education Strategy (Education Council, 2015). Each of these principles has been unpacked for teachers and the community in more detail on the Department's website, and units of work shared for use by teachers throughout the state from both the Department schools and the other Independent and/ or faith-based schools.

The approach draws upon the fact that almost one third of Tasmania's land area $(\sim 68,000$ square kilometres) is consigned to agriculture. In recognition of the importance of this (STEMrich) sector to the state, the government has supported the creation of new subjects for years 11 and 12 in Tasmanian Agricultural Education. These subjects are part of the Tasmanian Agricultural Education Framework (2016), which underpins the curriculum, career connections and stakeholder partnerships as enablers of learning from Preparation to Year 12. It was collaboratively developed by the Department of Primary Industries, Parks, Water and the Environment (DPIPWE), the Department of Education and the Hagley Farm School: Centre for Agricultural Education. In order to realise the potential of the framework, the Tasmanian Government has invested in professional learning, and has promised 250 additional teachers and 80 teacher assistants in its public schools, with $\$ 4.9$ million invested over a period of 4 years to provide 10 new teaching staff to support Farm Schools (e.g., Hagley Farm School) as well as further money to support the operational costs of running the farms. This acknowledgement of the importance of agriculture for the prosperity of the state provides a wonderful springboard for STEM-rich activities that have real world relevance to students.

Further to STEM, there is a recognition of and interest in STEAM and wider interdisciplinary education initiatives. In 2018, the University of Tasmania partnered with the Department of Education (DoE) to deliver a STEAM professional learning event, STEAM Horizons. This collaborative delivered its initial pilot implementation activity in 2018 as a multi-site, live streamed professional learning event (The STEAM Horizons Symposium) for a group of 70 teachers across Tasmania. Live streaming between school venues in the north, south, and north west generated a virtual community of practice. The STEAM Horizons professional learning collaborative team delivered an event which early evaluation suggests successfully empowered teachers and students, through showcasing the ways in which teachers around the state are enacting STEAM teaching and learning in their respective school contexts. Such was the success of and support for the 2018 symposium; a 2019 iteration is currently being developed for delivery later in the year.

The STEAM Horizons 2018 professional learning initiative, along with its associated research evaluations and publications (MacDonald et al., 2018; MacDonald \& Polley, 2019), have enabled University of Tasmania and the DoE to start working more closely, fostering rapport between Arts education pre-service education, arts education professional learning associations, and the DoE Curriculum Leader for The Arts. In collaborating with key education stakeholders to develop a working definition (MacDonald et al., 2018) for how we were observing and experiencing STEAM education to unfold in Tasmania, we created a holding space for possibility, reflection and transformation. The STEAM Horizons professional learning collaborative situates itself in reference to The Education Workforce Roundtable Declaration (2018) priorities; which call for the University 
of Tasmania to work in partnership with the Tasmanian Government and wider community to bring about educational transformation. This agenda is strengthened through the creation of links between the University, schools, colleges and TasTAFE; to build "educational aspiration and participation and improved educational outcomes in all regions of Tasmania" (Department of Education, 2018, p. 2)

\section{Victoria}

While outcomes from the current initiatives being implemented in K-12 STEAM education are yet to flow through to students entering into university education, the tertiary sector has been engaged with similar interdisciplinarity enactment concerns for some time. In Victoria, the 'Melbourne Model' was launched at the University of Melbourne in 2008 (Devlin, 2008). In the Australian context this was a ground breaking, breadth-driven undergraduate curriculum that promoted multidisciplinary learning experiences. Several leading universities subsequently followed suit with either very similar iterations of the 'Melbourne Model' (University of Western Australia), or, enterprise-scale curriculum renewal to embed breadth offerings (including Australian National University, Monash University).

While the Melbourne Model does not identify or prioritise specifically STEAM or other expanded-STEM discipline groupings, it aims to produce forward-thinking graduates who are skilled and resilient:

"A Melbourne degree provides graduates with in-depth knowledge of their specialist disciplines and skills in examining issues with multiple disciplinary perspectives. Melbourne graduates are critical, creative thinkers with strong reasoning skills. They can apply knowledge, information and research skills to complex problems in a range of contexts and are effective oral and written communicators. The Melbourne educational experience prepares graduates to be entrepreneurial and innovative thought-leaders. Melbourne graduates bring research and inquiry skills to challenges in their workplaces and communities. They are adept lifelong learners who generate bold and novel ideas by critically evaluating alternative possibilities and viewpoints" (University of Melbourne, 2019, para. 3-4)

This ambition aligns with research on the importance for graduates of so-called 'soft' skills, including creativity, critical reflection, communication and collaboration (Jefferson \& Anderson, 2017). Through the breadth emphasis of degree structures such as the Melbourne Model (typically found at Australian Qualifications Framework Level 7), students are encouraged to engage with a wide range of epistemologies, gaining experience across Biglan's (1973) 'hard and soft', 'applied and pure' discipline paradigms, later described by Kolb's (1981) learning style index of 'abstractconcrete' and 'active-reflective' orientations of academic fields. Familiarity with different approaches to knowledge construction, learning and problem solving are understood to be advantageous, developing the flexibility needed for graduates entering future industries.

The Melbourne model is an inversion of the common 'T-shaped' learning pathway, with broad (horizontal) undergraduate study complimented by deeper (vertical) learning within professional fields. Most professionally accredited courses, such as Architecture, require the Masters level qualifications to allow entry into the industry. As such, it shares the 'inverted T' pattern (Tregloan et al., 2016; 2018) of interdisciplinary education observed in the Australian K-12 curriculum, where there are generally greater opportunities for broader interdisciplinary learning (such as STEAM) in earlier schooling levels with a more focused, prescribed curriculum in senior year levels.

However, an important distinction is the "multiple disciplinary perspectives" associated with, in this example, the Melbourne Graduate. The integration of disciplinary domains and learning styles in, for example, play-based primary school STEAM pedagogy is a key feature of interdisciplinary learning (Davies \& Devlin, 2010), achieving the 'soft' skills of creativity, critical reflection, 
communication and collaboration identified by Kivunja (2015). However, this integration is by definition, absent in the multidisciplinary approach made explicit in the Melbourne Model; calling into question whether those soft, transferable skills are achieved.

\section{STEM and STEAM and the Spaces Between: Collective Implications of the Enablers and Inhibitors for Disciplinary Agendas Across Three Australian States}

The storied accounts presented in the following discussion emerged through a process of ongoing peer reflection, review and writing. The authorship team identified converging points for individual and collective stories (Clandinin, Connelly \& Chan, 2002) in diverse education contexts; storying in and through forms created as sites of sophisticated knowledge, in sites of higher knowledge (Phillips \& Bunda, 2018). This discussion unfolds from the three overarching questions previously discussed, that the authorship team collectively distilled to enable data generation, sharing and meaning making processes. These questions provided a lens through which the authors were able to determine the critical through lines, used to inform the assemblage of a 'bigger picture' multi sector collective vignette for our three states (NSW, TAS, VIC). The following discussion provides insight into how the authors collaboratively render the situational, temporal, and social aspects of deficit and/ or enabling storylines that have historically marginalised some disciplines at the expense of elevating others.

The various conceptualisations of disciplinary agendas articulated and examined in this article embrace approaches and philosophies that deeply impact teachers' own pedagogical acts of transformative learning (Tregloan et al., 2018). The approach resonates with Hatcher's compelling argument about teaching and learning needing to expand beyond simplistic notions of knowledge transfer and acquisition to embrace more enriching conceptions of relational and interdisciplinary education (Hatcher, 2011). Without such foundations, the story of innovative interdisciplinarity might only be a novelty as perceived by localised opinions of the virtue (or not) of bringing STEM and the gamut of other disciplines together (Stokes, 2018).

Emerging across the vignettes is the recognition that the teaching of integrated STEM or STEAM requires a change in teacher pedagogies to encompass real world problem solving or design-based approaches (Fraser et al., 2019). It is inherently risky for an individual teacher to move into a liminal space (such as interdisciplinary STEM), which by definition is one that is yet to be supported by rich, relevant and readily accessible resources. However, this risk-laden space offers immense potential for a truly relational and non-hierarchal education experience; one that is curious, provocative, disruptive and complex and is therefore worthy of our attentive perseverance. This complexity, which has the potential to serve as either an enabler or inhibitor, embraces the aspiration of transformative teaching and learning experiences. The challenge of leveraging the optimum degree of risk to generate innovation is a delicate balancing act. Fostering uncertainty whilst providing just enough definition, support and permission for teachers to feel adequately empowered, captures the precarity of the threshold upon which the vision for successful interdisciplinary education is located. Common agendas and priorities impacting upon STEM and STEAM education emerging across the three states compel teachers to dissolve and transcend disciplinary boundaries through enactment of emergent interdisciplinary pedagogies that generate interdisciplinary learning outcomes. What happens in the spaces between STEM and STEAM disciplinary intersections emerges as an integral space, within which risk, mess and disruption foster key $21^{\text {st }}$ century skills in teaching and learning, industry and life. Several significant challenges exist for teachers seeking to enact the necessary pedagogical transformations required to achieve meaningful and authentic interdisciplinary STEM and STEAM education outcomes in Australia. The deeply entrenched disciplinary privileging and siloing that characterises the current schooling system - particularly in the secondary context - is 
highly problematic (MacDonald, 2019). Before teachers can collectively engage in the authentic interdisciplinary collaboration necessary to dissolve disciplinary barriers, the organisational structures within and from which the majority of Australian schools operate are already in conflict with this aspiration. Here, attention to the 'spaces between' might help elicit what is missing, by identifying what is essential to achieve 'stated' education aspirations. For teachers to be able to mobilise the three-dimensions of the Australian Curriculum in ways that allow for an authentic entwinement of disciplinary skills, capabilities and ways of knowing, they need to be empowered to improvise and challenge their own practices, try new working methods, and break routines without fear of criticism and punishment (Harris \& de Bruin, 2017). Across the three states, there is insufficient evidence of planned or equivalent structural or systemic change that will better support teachers to 'meet' the postulated pedagogical transformations necessary for STEM and STEAM education to thrive.

How to assess students in these spaces is largely absent within all of the agendas. This key observation emerges as a major inhibitor; an 'elephant in the classroom', in terms of impacting the lived activation and mobilisation of STEM and STEAM. For example: there are no stand-alone places to report interdisciplinary learning within half-yearly and annual documentation in New South Wales, Tasmanian and Victorian schools. Teachers are not able to specifically assess and report STEM or STEAM learning outcomes. The structure of most school assessment systems has not yet adopted the revisions necessary to meet the innovative pedagogical transformations being promoted in STEM education strategies. Teacher comments or a lone assessment mark in school reports for example, are common. Finding ways to formally assess, capture and value these liminal spaces must be prioritised.

\section{Future Directions Pertaining to 'Disciplinarity' Across Three Australian States: A Wish}

\section{List}

Emerging from this discussion spanning three Australian states is the need for a collective commitment to action. The emphasis on disciplinary agendas in political and policy frameworks for education might well be paused, to better reflect on the X-shaped teachers required to embolden $\mathrm{X}$-shaped learners, through clearly articulated, inclusive and enabling expectations. This notion of the ' $X$ ' shaped individual - where ' $X$ ' can also function as being resistant to, or yet to be defined - establishes a liminal space in which the possibilities for future interdisciplinary directions can be considered. In closing, this article summarises the gauntlet laid down by the collective analysis the disciplinary agendas and priorities of three states.

In NSW questions remain about how the STEM push will continue to gain momentum if sustained funding for teacher professional learning is not highlighted in state budgets. The very nature of STEM and STEAM as resource intensive fields, where access to materials, disciplinary expertise from outsiders, alongside continued opportunities to build capacity of teachers must support the profession's enthusiasm to date. End of schooling credentialing structures like ATAR (Australian Tertiary Admissions Ranking) and the NSWHSC (Higher School Certificate) act as systemic hurdles, and while STEM and STEAM projects, programs and inquiry in the K-10 years of schooling are providing innovative learning opportunities for young people, their ubiquitous experiences are constrained or at significant risk of being unravelled in the final siloed years of secondary education.

Furthermore, the University of Technology Sydney (UTS) has a bespoke Faculty of Transdisciplinary Innovation, where programs are designed to meet the needs of industry for novel approaches to complex applied problems. This development is applauded and through its example of success, places more pressure on school systems to align and pay attention to the kinds of learners that will more seamlessly move into such courses with strong interdisciplinary foundations.

Tasmania is characterised by its socio-economic and cultural complexity that concurrently derives from and impacts on education outcomes for students and communities. In 2016, the 
Australian Bureau of Statistics reported that only 51\% of the Tasmanian population held a post-school qualification, while a more recent report from the Australian Council of Social Service (Davidson, Saunders, Bradbury \& Wong, 2018) highlighted that more than 120,000 people $(23.6 \%)$ in the state are living in poverty, including $15.8 \%$ of children aged under 15 years. Education is acknowledged as key to addressing poverty in Tasmania. The STEM strategies developed across the state are underpinned by the aspiration to transform the cultures that continue to inhibit educational attainment, aspiration and wellbeing. The translation of a STEM vision into real world applied learning opportunities is apparent in pockets, however is uneven and contingent upon State government's preparedness to continue investing in the STEM-centric professional learning essential to support schools and teachers. In addition, a lack of attention has been given to the implications of siloed structures of secondary schooling to ascertain how they enable and/or inhibit interdisciplinary education agendas. Enabling collaboration across disciplines underpins the capacity to re-conceptualise education agendas in Tasmania.

In Victoria, there are ongoing concerns regarding perceived misalignment between the interdisciplinary learning outcomes desired by the tertiary sector from STEAM and other discipline combinations, and the pedagogies employed. Successes have much in common with early childhood and primary schooling models; however, in parallel to the secondary education sector narratives in New South Wales and Tasmania, the primary challenge is the professional support, structure and leadership required to allow teachers time, space and resources to speculate, experiment and innovate. Without this capacity, the ability to deliver work-ready graduates for future industries is challenging.

Universities need to prioritise the promotion of genuine inter and transdisciplinary studies within Faculties of Education; studies that are concurrently underpinned by and informing the future shaping of authentic inter and transdisciplinary teaching and learning experiences. When desired outcomes for learners embody, activate and enact the full spectrum of disciplinary mindsets, be these STEM, STEAM or other disciplinary assemblages that mobilise the breadth and depth of disciplinary fields of knowledge and ways of knowing, then it may be possible to realise the full potential of the Australian Curriculum. Alignment across all levels of education is possible through collaboration where leadership, resource sharing and stakeholder engagement prioritises inclusive disciplinary perspectives and language.

Re-inscribing tensions between disciplines by fixating on arguments over the assemblage of particular disciplinary hierarchies are a disservice to our collective realisation of interdisciplinary aspirations. In saying this, disciplinary acronyms are without doubt playing an important step in enabling articulation of our journey towards fostering interdisciplinary visions for transformative education outcomes. In order to avoid getting caught up in the battles of disciplinary hierarchy, education across all levels has an important role to play in how we work with teachers, students, researchers, industry and communities to be more collective and collaborative with these tensions. The spaces between disciplines, and levels of education, can create spaces in which we can step outside our respective contexts to look at how disciplinary hegemony, privilege and marginalisation are shaping our education system. Such contemplation is necessary if we are to get a genuine sense of how our enactment of disciplinary agendas is 'making way' or 'getting in the way' of the collective work we need to do together.

\section{References}

Australian Bureau of Statistics. (2016). Media Release: Australians pursuing higher education in record numbers. Retrieved from http://www.abs.gov.au/AUSSTATS/abs@.nsf/mediareleasesbyReleaseDate/1533FE5A8541D66CC A2581BF00362D1D?OpenDocument

Australian Curriculum, Assessment and Reporting Authority (2017). Structure of the Australian Curriculum. Retrieved from https://www.australiancurriculum.edu.au/f-10-curriculum/structure/ 
Allen, J. M. Wright, S. Cranston, N. Watson, J. Beswick, K. \& Hay, I. (2018). Raising levels of school student engagement and retention in rural, regional and disadvantaged areas: is it a lost cause? International Journal of Inclusive Education, 22(4), 409-425.

Beattie, M. (1995). New prospects for teacher education: Narrative ways of knowing teaching and teacher learning. Educational Research, 37(1), 53-70.

Beswick, K., Fraser, S., Crowley, S. (2016). 'No wonder out-of-field teachers struggle!' - Unpacking the thinking of expert teachers. Australian Mathematics Teacher, 72(4), 16-20.

Bequette, J. W., \& Bequette, M. B. (2012). A place for art and design education in the STEM conversation. Art Education, 65(2), 40-47.

Biglan, A. (1973). The characteristics of subject matter, Journal of Applied Psychology, 57(3), 195-203.

Clandinin, D. J., Connelly, F. M., \& Chan, E. (2002). Three narrative teaching practices - One narrative teaching exercise. In N. Lyons \& V. K. LaBoskey (Eds.). Narrative inquiry in practice: Advancing the knowledge of teaching (pp. 133 145). Columbia, SC: Teachers College Press.

CommSec Research (2018). What's the economic state of our states? Retrieved from https://www.commbank.com.au/ guidance/economy/commsec-state-of-the-states-report-january-2018-201801.html

Commonwealth of Australia. (2017). Innovation and Creativity: Inquiry into innovation and creativity: workforce for the new economy. Parliament of the Commonwealth of Australia. Canberra, Australia: Government Printers.

Colucci-Gray, L., Trowsdale, J., Cooke, C. F., Davies, R., Burnard, P., \& Gray, D. S. (2017). Reviewing the potential and challenges of developing STEAM education through creative pedagogies for 21st learning: How can school curricula be broadened towards a more responsive, dynamic, and inclusive form of education? Retrieved from https://jotrowsdale.files.wordpress.com/2017/11/bera-research-commission-report-steam.pdf

Colucci-Gray, L., Burnard, P., Gray, D., \& Cooke, C. (2019). A critical review of STEAM (Science, Technology, Engineering, Arts, and Mathematics). In P. Thomson (Ed.), Oxford Research Encyclopedia of Education. Oxford, United Kingdom: Oxford University Press. DOI: 10.1093/acrefore/9780190264093.013.398

Costantino, T. (2018). STEAM by another name: Transdisciplinary practice in art and design education. Arts Education Policy Review, 119(2), 100-106.

Craft, A. (2011). Creativity and education futures: Learning in a digital age. Stoke-on-Trent, United Kingdom: Trentham Books.

Cunningham, S. (2018). An exploding creative economy shows innovation policy shouldn't focus only on STEM. The Conversation. Retrieved from https://theconversation.com/an-exploding-creative-economy-shows-innovationpolicy-shouldnt-focus-only-on-stem-93732

Cunningham, A. E., Perry, K. E., Stanovich, K. E., \& Stanovich, P. J. (2004). Disciplinary knowledge of K-3 teachers and their knowledge calibration in the domain of early literacy. Annals of dyslexia, 54(1), 139-167.

Davidson, P., Saunders, P., Bradbury, B. \& Wong, M. (2018). Poverty in Australia, 2018. ACOSS/UNSW Poverty and Inequality Partnership Report No. 2, Sydney, Australia: ACOSS.

Davies, M., \& Devlin, M. (2010). Interdisciplinary higher education. In M. Davies, M. Devlin, \& M. Tight (Eds.), Interdisciplinary higher education: Perspectives and practicalities (pp. 3-28). Bingley, United Kingdom: Emerald House Publishing.

Department of Premier and Cabinet. (2018). Communities, sport and recreation. Retrieved from http://www.dpac.tas.gov. $\underline{\mathrm{au} / \text { divisions/csr }}$

Devlin, M. (2008). International and interdisciplinary approach to curriculum: The Melbourne model. In U21 Teaching \& Learning Conference, Universitas 21, February 21-22. Glasgow, Scotland.

Dilkes, J., Cunningham, C., \& Gray, J. (2014). The new Australian Curriculum, teachers and change fatigue. Australian Journal of Teacher Education, 39(11), Article 4.

Education Council (2015). National STEM school education strategy, 2016-2026. Retrieved from: http://www. educationcouncil.edu.au/site/DefaultSite/filesystem/documents/National\%20STEM $\% 20$ School $\% 20$ Education $\% 20$ Strategy.pdf

Fraser, S., Earle, J., Fitzallen, N. (2019). What is an acronym? Experiencing STEM education in Australia. In T. Barkatsas, N. Carr, \& G. Cooper (Eds.), STEM education: An emerging field of inquiry (pp. 9-30). Leiden, The Netherlands: Koninklijke Brill.

Gotsis, T. (2017). STEM education in NSW Schools. Sydney, Australia: NSW Parliamentary Research Service.

Grimmer, L. (2017). Re-inventing Central Launceston: Creating a vibrant and thriving regional city. ABC Radio, Tasmanian Northern Breakfast Program with Belinda King, Australian Broadcasting Corporation, Australia, 1 November 1, 2017.

Harris, A., \& de Bruin, L. (2017). STEAM education: Fostering creativity in and beyond secondary schools. Australian Art Education, 38(1), 54. 
Hatcher, R. (2011). Professional learning for creative teaching and learning. In Sefton-Green, J., Thomson, P., Jones, K., \& Bresler, L. (Eds.), The Routledge international handbook of creative learning (pp. 404 - 413). Milton Park, United Kingdom: Routledge.

Hobbs L., Clark J. C., \& Plant B. (2018). Successful students - STEM program: Teacher learning through a multifaceted vision for STEM education. In R. Jorgensen \& K. Larkin (Eds.), STEM education in the junior secondary: The state of play. Singapore: Springer.

Huber, M. T., Hutchings, P., \& Gale, R. (2005). Integrative learning for liberal education. Peer Review, 7(3/4).

Huberman, M. (1995). Networks that alter teaching: Conceptualizations, exchanges and experiments. Teachers and Teaching, 1(2), 193-211.

Hunter, J. (2013). Exploring technology integration in teachers' classrooms in NSW public schools. [Unpublished doctoral thesis]. Sydney, Australia: University of Western Sydney.

Hunter, J. (2015). Technology integration and High Possibility Classrooms: Building from TPACK. New York, NY: Routledge.

Hunter, J. (2017). Switching middle school teachers onto STEM using a pedagogical framework for technology integration: The case for High Possibility Classrooms in Australia. In L. Liu \& D. D. Gibson (Eds.), Research highlights in technology and teacher education 2017 (pp. 37-46). Waynesville, NC: AACE.

Jefferson, M., \& Anderson, M. (2017). Transforming schools: Creativity, critical reflection, communication, collaboration. London, United Kingdom: Bloomsbury Publishing.

Kivunja, C. (2014). Do you want your students to be job-ready with 21 st century skills? Change pedagogies: A pedagogical paradigm shift from Vygotskyian social constructivism to critical thinking, problem solving and Siemens' digital connectivism. International Journal of Higher Education, 3(3), 81-91.

Kolb, D. A. (1981). Experiential learning theory and the learning style inventory: Areply to Freedman and Stumpf. Academy of Management Review, 6(2), 289-296.

Leggo, C. (2008). Autobiography: Researching our lives and living our research. In S. Springgay, R. L. Irwin, C. Leggo. \& P. Gouzouasis (Eds.). Being with a/r/toraphy (pp. 3-25). Rotterdam, The Netherlands: Sense Publishers.

Lehman, K. F. \& Reiser, D. (2014). The nexus between an art experience and creative tourism: Tasmania's Museum of Old and New Art. Mondes du Tourisme, 10(2),19-32.

Levi-Strauss, C. (1962). The savage mind. Chicago, IL: University of Chicago Press.

Liao, C. (2016). From interdisciplinary to transdisciplinary: An arts-integrated approach to STEAM education. Art Education, 69(6), 44-49.

Loble, L., Creenaune, T., \& Hayes, J. (2017). Future frontiers; Education for an AI world. Melbourne, Australia: Melbourne University Press and the NSW Department of Education.

MacDonald, A. (2019). STEM, STEAM and the in-between: Explicating the enablers and inhibitors of interdisciplinary teaching, 2019 Australian Teacher Educator Association Conference, $5^{\text {th }}$ July, University of the Sunshine Coast, Sippy Downs, Sunshine Coast, Australia

MacDonald., A., Baguley, M., \& Kerby, M. (2017). Collaboration as metaphoric construct and guiding practice in artmaking and teaching: A multi-modal rendering. Studies in Art Education, 58(4), 312-324.

MacDonald, A., Hunter, M. A, Ewing, R., \& Polley, J. (2018). Dancing around drawn edges: Reimagining storylines as sites for relational Arts teacher professional learning collaboration. Australian Art Education, 39(3), 455-467.

MacDonald, A., \& Polley, J. (2019). Collaboration, consultation and co-design: Empowering Arts teachers to embrace and enact the Australian Curriculum - The Arts - A Tasmanian perspective. National Visual Art Education Conference, Canberra, January 21-23. National Gallery of Australia.

MacDonald, A., \& Wightman, K. (in press). Cultivating professional learning partnerships in Tasmania, in B. Shelley, K. te Riele, \& N. Brown (Eds). Harnessing transformative power of education. Leiden, The Netherlands: Koninklijke Brill.

MacDonald, A., \& Wise, K. (2018). Stemming the flow of STEAM, LoudMouth eZine, The Music Trust. Retrieved from http://musictrust.com.au/loudmouth/stemming-the-flow-of-steam/

MacDonald, A., Wise, K., Holmstrom, N. G., Brown. N., \& Polley, J. (2018). Disrupting disciplines: Empowering students and teachers to drive STEAM teacher professional learning design. Teaching Matters 2018, 21 November 2018, Launceston, Tasmania.

Marshall, J. (2014). Transdisciplinarity and art integration: Toward a new understanding of art-based learning across the curriculum. Studies in Art Education, 55(2), 104-127.

McCarthy, K. F., Ondaatje, E. H., Zakaras, L., \& Brooks, A. (2001). Gifts of the muse: Reframing the debate about the benefits of the arts. Santa Monica, CA: Rand Corporation. 
Mohr-Schroeder, M. J., Cavalcanti, M., \& Blyman, K. (2015). STEM education: Understanding the changing landscape. In A. Sahin (Ed.), A practice-based model of effective science, technology, engineering and mathematics (STEM) education teaching, Boston, MA: Sense.

Moore, T. J. Johnson, C., Peters-Burton, E. E., \& Guzey, S. S. (2016). The Need for a STEM road map. In T. J. Moore, C. C. Johnson, E. E. Peters-Burton, \& S. S. Guzey (Eds.), STEM road map: A framework for integrated STEM education (pp. 3-22). New York, NY: Routledge.

National Advocates for Arts Education. (2018). Arts educators call for a visionary approach to arts education and creative work: Media release. Retrieved from http://ausdance.org.au/news/article/arts-educators-call-for-a-visionaryapproach-to-arts-education-and-creative

New South Wales Department of Education. (2017). Principles of learning and integrating STEM education pedagogy. Retrieved from http://www.stem-nsw.com.au/teaching-stem/principles-of-stem-education

New South Wales Department of Education (2018). Learning for the Future: STEM. Retrieved from https://education. nsw.gov.au/teaching-and-learning/curriculum/learning-for-the-future/stem

New South Wales Department of Finance, Services and Innovation. (2018). Annual Report 2017/2018. Retrieved from https://www.finance.nsw.gov.au/sites/default/files/dfsi annual_report2017-18.pdf

Paretti, M. (2011). Interdisciplinarity as a lens for theorizing language/content partnerships. Across the Disciplines, 8(3), 299.

Park, H., Byun, S. Y., Sim, J., Han, H., \& Baek, Y. S. (2016). Teachers' perceptions and practices of STEAM education in South Korea. Eurasia Journal of Mathematics, Science \& Technology Education, 12(7), 1739-1753.

Phillips, L. G., \& Bunda, T. (2018). Research through, with and as storying. London, United Kingdom: Routledge.

Radziwill, N. M., Benton, M. C., \& Moellers, C. (2015). From STEM to STEAM: Reframing what it means to learn. The STEAM Journal, 2(1), Article 3. DOI: 10.5642/steam.20150201.3

Saldaña, J. (2009). The coding manual for qualitative researchers. Thousand Oaks, CA: Sage.

Savage, G. C. (2016). Think tanks, education and elite policy actors. The Australian Educational Researcher, 43(1), 3553.

Savage, G. C. (2019). What is policy assemblage? Territory, Politics, Governance, [Online first] https://doi.org/10.1080 $/ 21622671.2018 .1559760$

Savage, G. C., \& Lewis, S. (2018). The phantom national? Assembling national teaching standards in Australia's federal system. Journal of Education Policy, 33(1), 118-142.

Stokes, R. (2018). STEM has become a buzzword and a fad: NSW education minister, The Sydney Morning Herald, Fairfax media, March 21. Retrieved from https://www.smh.com.au/politics/nsw/stem-has-become-a-buzzword-and-a-fadnsw-education-minister-20180321-p4z5iw.html

Stratford, E., Field, M., Grant, O., \& Ambrose, K. (2016). Summary of insights of three round-figure discussions on educational attainment in Tasmania incorporating the involvement of Honourable Henry De Sio Jr. Retrieved from http://www.utas.edu.au/_data/assets/pdf_file/0009/892521/Underwood_2016RoundFigure_EdAttain.pdf

Tasmanian Department of Education. (2016). Grow, make, protect: Tasmanian Agricultural Education Framework. Retrieved from https://documentcentre.education.tas.gov.au/Documents/Tas\%20Ag\%20Framework $\% 20$ FINAL\%20WEB.pdf

Tasmanian Department of Education. (2015). STEM Education Strategy. Retrieved from https://stem.education.tas.gov. $\mathrm{au} /$

Tasmanian Department of Education. (2017). STEM Framework. Retrieved from https://documentcentre.education.tas. gov.au/Documents/115_17_STEM\%20Framework_Final\%2019122017.pdf

Tasmanian Department of Education. (2018). The Education Workforce Roundtable Declaration (2018). Retrieved from: https://documentcentre.education.tas.gov.au/Documents/Education-Workforce-Roundtable-Declaration.pdf

Taylor, P. C. (2016). Why is a STEAM curriculum perspective crucial to the 21st century? Retrieved from https:// researchrepository.murdoch.edu.au/id/eprint/37950/1/STEAM.pdf

Timms, M., Moyle, K., Weldon, P., \& Mitchell, P. (2018). Challenges in STEM learning in Australian schools: Literature and policy review. Camberwell, Australia: ACER. Retrieved from https://works.bepress.com/pru_mitchell/38/ download/

Tregloan, K., Wise, K., \& Fountain, W. (2016). Multiple measures and interdisciplinary adventures: Benchmarking interdisciplinary assessment design in the Creative Arts and Humanities. In ACUADS 2016 Conference proceedings, Brisbane, Australia, Sept 29-30.

Tregloan, K., Wise, K., \& Fountain, W. (2018). Multiple measures: A tool for supporting inter-disciplinary assessment design. In S. Griffith, K. Carruthers, \& M. Blimel (Eds). Visual tools for developing cross-disciplinary collaboration, innovation and entrepreneurship capacity (pp. 371-392). Champaign, IL: Common Ground Research Networks. 
Tytler, R., Williams, G., Hobbs, L., \& Anderson, J. (2019). Challenges and opportunities for a STEM interdisciplinary agenda. In Interdisciplinary Mathematics Education (pp. 51-81). Cham, Switzerland: Springer

University of Melbourne. (2019). The Melbourne Model: A different way of thinking, Retrieved from https://study. unimelb.edu.au/study-with-us/our-degrees

Webster, L., \& Mertova, P. (2007). Using narrative inquiry as a research method: An introduction to using critical event narrative analysis in research on learning and teaching. New York, NY: Routledge.

Yakman, G. (2008). STEAM education: An overview of creating a model of integrative education. In Pupils' Attitudes Towards Technology (PATT-19) Conference: Research on Technology, Innovation, Design \& Engineering Teaching (pp. 335-358). Salt Lake City, United States of America.

Yakman, G., \& Lee, H. (2012). Exploring the exemplary STEAM education in the US as a practical educational framework for Korea. Journal of the Korean Association for Science Education, 32(6), 1072-1086.

Yoder, S., Bodary, S., \& Johnson, C. C. (2016). Effective program characteristics, start-up and advocacy for STEM. In C. C. Johnson, E. E Peters- Burton, \& T. J. Moore (Eds.), STEM road map: A framework for integrated STEM education (pp. 211-237). New York, NY: Routledge. 